\title{
ReVIEW
}

\section{Regulation of TLR7/9 signaling in plasmacytoid dendritic cells}

\author{
Musheng Bao ${ }^{\bowtie}$, Yong-Jun Liu \\ Baylor Institute for Immunology Research, Dallas, TX 75204, USA \\ $\square$ Correspondence: Musheng.Bao@baylorhealth.edu (M. Bao), Yong-Jun.Liu@baylorhealth.edu (Y.-J. Liu) \\ Received October 5, 2012 Accepted October 11, 2012
}

\begin{abstract}
Plasmacytoid dendritic cells (pDCs), also known as type I interferon (IFN)-producing cells, are specialized immune cells characterized by their extraordinary capabilities of mounting rapid and massive type I IFN response to nucleic acids derived from virus, bacteria or dead cells. PDCs selectively express endosomal Toll-like receptor (TLR) 7 and TLR9, which sense viral RNA and DNA respectively. Following type I IFN and cytokine responses, pDCs differentiate into antigen presenting cells and acquire the ability to regulate $T$ cell-mediated adaptive immunity. The functions of pDCs have been implicated not only in antiviral innate immunity but also in immune tolerance, inflammation and tumor microenvironments. In this review, we will focus on TLR7/9 signaling and their regulation by $\mathrm{pDC}$-specific receptors.
\end{abstract}

KEYWORDS plasmacytoid dendritic cells, Toll-like receptors, immunoreceptor tyrosine-based activation motif, immunoreceptor tyrosine-based inhibitory motif, immunoglobulin-like transcript, BDCA2, phospholipid scramblase 1, protein kinase $\mathrm{C}$ and casein kinase substrate in neurons 1

\section{INTRODUCTION}

The innate immune system senses microbial infection or tissue damage by pattern recognition receptors (PRRs), which include Toll-like receptors (TLRs), RIG-I-like receptors I helicases, NOD-like receptors, and C-type lectin receptors. PRRs recognize structures conserved among microbial species, known as pathogen-associated molecular patterns. PRRs are also responsible for recognizing endogenous molecules released from damaged cells, damage-associated molecular patterns (Takeuchi and Akira, 2010). In contrast to myeloid dendritic cells that express TLR1, TLR2 and TLR3, pDCs selectively express TLR7 and TLR9 within the en- dosomal compartments, where they engage with their RNA or DNA agonists and activate downstream signaling pathways (Kadowaki et al., 2001). Upon ligands engagement, TLR7/9 recruit the key adaptor molecule MyD88 through their Toll/IL1 receptor (TIR) domains. MyD88 recruits IL-1 receptor-associated kinase (IRAK) to TLRs through interaction of the death domains of both molecules. IRAKs are activated by phosphorylation, associate with the TNF receptor-associated factor (TRAF) domain of TRAF6 and dissociates from the receptor. Then, IRAKs/TRAF6 complex associates with transforming growth factor- $\beta$-activated protein kinase 1 (TAK1) and leads to the activation of NF-KB and mitogen-activated protein kinases (MAPKs). In addition, IRAKs/TRAF6 complex also leads to the activation of interferon regulatory factor 7 (IRF7), the master regulator of type I IFN production. The activation of IRF7 requires multiprotein complex including IRAK4, IRAK1, TRAF6, TRAF3, IKB kinase a (IKKa) (Akira and Takeda, 2004; Gilliet et al., 2008). In pDCs, engagement of TLR9 by type A CpG DNA in the early endosomes preferentially triggers the IRF7 signal cascade, leading to type I IFN responses; whereas engagement of TLR9 by type B CpG DNA in the late endosomes preferentially triggers the NF-KB/ MAPKs signal cascade, leading to the production of proinflammatory cytokines TNFa and IL6 (Honda et al., 2005a; Guiducci et al., 2006). PDCs express several surface receptors, such as blood dendritic cell antigen 2 (BDCA2) and immunoglobulin-like transcript 7 (ILT7) in human $\mathrm{pDCs}$ and Siglec-H and Ly49Q in mouse pDCs that can modulate TLR7/9 signaling pathways. In addition, many other proteins, including microbial-derived molecules have also been shown to regulate TLR7/9 signaling.

\section{ITAM-ASSOCIATED SURFACE RECEPTORS}

Immunoreceptor tyrosine-based activation motifs (ITAMs), which contain the consensus sequence $\mathrm{YxxL} / \mathrm{I}-(\mathrm{x})_{6-8}-\mathrm{YxxL/I}(\mathrm{x}$ denotes any amino acid), are used by multiple receptors to 
activate immune cells. ITAM-containing transmembrane signaling adaptors include the TCR-associated CD3y, CD3ठ, $\mathrm{CD} 3 \varepsilon$, and $\mathrm{CD} 3 \zeta$ chains; BCR-associated Ig $\alpha$ and Ig $\beta$ chains; the FceRI $\beta$ chain; the FceRI-, the FcyRI-, and the FcyRIII-associated $\mathrm{Y}$ chain; and DNAX activation protein 12 (DAP12). Classically, ITAMs induce activation signals that involve phosphorylation of the tyrosines within the ITAMs and recruitment of Syk family tyrosine kinases. However, recent studies have shown that ITAMs also transduce inhibitory signals that negatively regulate production of proinflammatory cytokines by myeloid cells (Pasquier et al., 2005; Hamerman and Lanier, 2006; Ivashkiv, 2011).

\section{PDC-RECEPTOR ILT7}

Among the ITAM-containing adaptor molecules, FcERIy and DAP12 are expressed on pDCs. Several human pDC surface receptors were found to form complexes with FcERIy. ILT7, also known as leukocyte Ig-like receptor A4 (LILRA4), is a member of LILR family and associates with FcERly to transduce the ITAM signaling (Cao et al., 2006). LILR family members contain two to four C2-type Ig like domains and can be further divided into two groups. The LILRA group has six members (LILRA1 to LILRA6) that have charged residue in the transmembrane domain and a short cytoplasmic domain (except for LILRA3, that lacks the transmembrane domain). The charged residue in the transmembrane domains of LILRA members allow them to associate with ITAM-containing adaptor molecules to activate downstream signaling after ligand engagement or antibody crosslinking (Brown et al., 2004). The LILRB group has five members (LILRB1 to LILRB5) that contain immunoreceptor tyrosine-based inhibitory motifs (ITIMs) in their cytoplasmic domain. ILT7 is a member of the LILRA subfamily that is selectively expressed on human pDCs within the immune system. Crosslinking of ILT7 by immobilized anti-ILT7 monoclonal antibody induces ITAM-mediated signaling cascade similar to $\mathrm{B}$ cell receptor signaling cascade, which negatively regulates the TLR7/9-induced type I IFN and cytokine responses (Cao et al., 2006). Bone marrow stromal cell antigen 2 has been identified as the physiological ligand for ILT7 that inhibits TLR-induced cytokine responses by pDCs (Cao et al., 2006; Cao et al., 2009). In addition, pDCs also express FceRla, the high-affinity receptor for the Fc region of IgE. Engagement of FceRla by IgE leads to the inhibition of CpG DNA-induced type I IFN production by pDCs via FceRly (Schroeder et al., 2005). Consistent with these observations, knockdown of FceRly and Syk in a pDC cell line, Gen2.2 cells, enhances TLR9-mediated type I IFN production and reverses ITAM-triggered inhibition (Bao et al., 2012) (Fig. 1). How ITAM signaling intersects and negatively regulates TLR7/9mediated responses in pDCs remains elusive. Other LILRA family members like ILT1 (also known as LILRA2) and ILT11 (also known as LILRA5) can also associate with FceRly and function as activating receptors in human monocytes and macrophages (Nakajima et al., 1999; Mitchell et al., 2008). Their functions in pDCs remain unknown.

\section{PDC-RECEPTOR BDCA2}

BDCA2, a type II C-type lectin uniquely expressed on human pDCs, is another pDC-specific surface receptor that forms complex with FceRly (Cao et al., 2007). Crosslinking of BDCA2 triggers the ITAM signaling pathway through FceRly and inhibits TLR7/9 induced responses (Cao et al., 2007; Rock et al., 2007). HIV-1 encoded envelope glycoprotein gp120 is shown to be a potential ligand for BDCA2 that inhibits TLR9-mediated activation and IFNa secretion (Martinelli et al., 2007; Lo et al., 2012).

Recently, we have shown that CD2 associated adaptor protein (CD2AP) that is highly expressed in pDCs positively regulates the BDCA2-induced ITAM signaling pathway. CD2AP belongs to the CIN85/CD2AP family that includes CIN85 and CD2AP, characterized by containing three $\mathrm{SH} 3$ domains in the $\mathrm{NH} 2$ terminus, a proline-rich domain in the center region and coil-coiled domain in the C-terminus. CIN85/CD2AP have been shown to regulate T-cell activation, kidney glomeruli function, apoptosis in neuronal cells and the degradation of receptor tyrosine kinases (Dikic, 2002). CD2AP forms a complex with SH2-containing inositol phosphatase-1 (SHIP1) via its first SH3 domain. The CD2AP/SHIP1 complex enhances BDCA2/FcERly signaling by inhibiting the E3 ubiquitin ligase activity of $\mathrm{Cbl}$ to maintain the expression level of Syk and FceRly that are key adaptors for the ITAM signaling pathway (Bao et al., 2012). This suggests that, compared to other immune cells, the ITAM signaling pathway may be regulated in a special way in human pDCs.

\section{DAP12-ASSOCIATED RECEPTORS}

In addition to FceRly, several surface receptors associate with the ITAM containing adaptor molecule DAP12 to transduce inhibitory signaling in pDCs. NKp44, an Ig superfamily member in human that is highly expressed on NK cells, is also present on pDCs in tonsils and on blood pDCs after culture with interleukin 3 (IL3). NKp44 associates with DAP12 and crosslinking of NKp44 inhibits type I IFN production by pDCs in response to CpG DNA. NKp44 recognizes the hemagglutinin of influenza virus and also the proliferating cell nuclear antigen that is overexpressed in cancer cells, suggesting virus and cancer cells may inhibit pDC function through ITAM-containing receptors (Arnon et al., 2001; Fuchs et al., 2005; Rosental et al., 2011). Leukocyte-associated Ig-like receptor-1, an ITIM-motif containing receptor that is highly expressed on pDCs, may have synergistic inhibitory effects with NKp44 (Bonaccorsi et al., 2010). Siglec-H, a sialic acid-binding Ig-like lectin molecule selectively expressed on mouse pDCs, associates and signals through the adapter DAP12. Ligation of Siglec-H using immobilized antibodies attenuates TLR9-induced type I IFN secretion. In ad- 


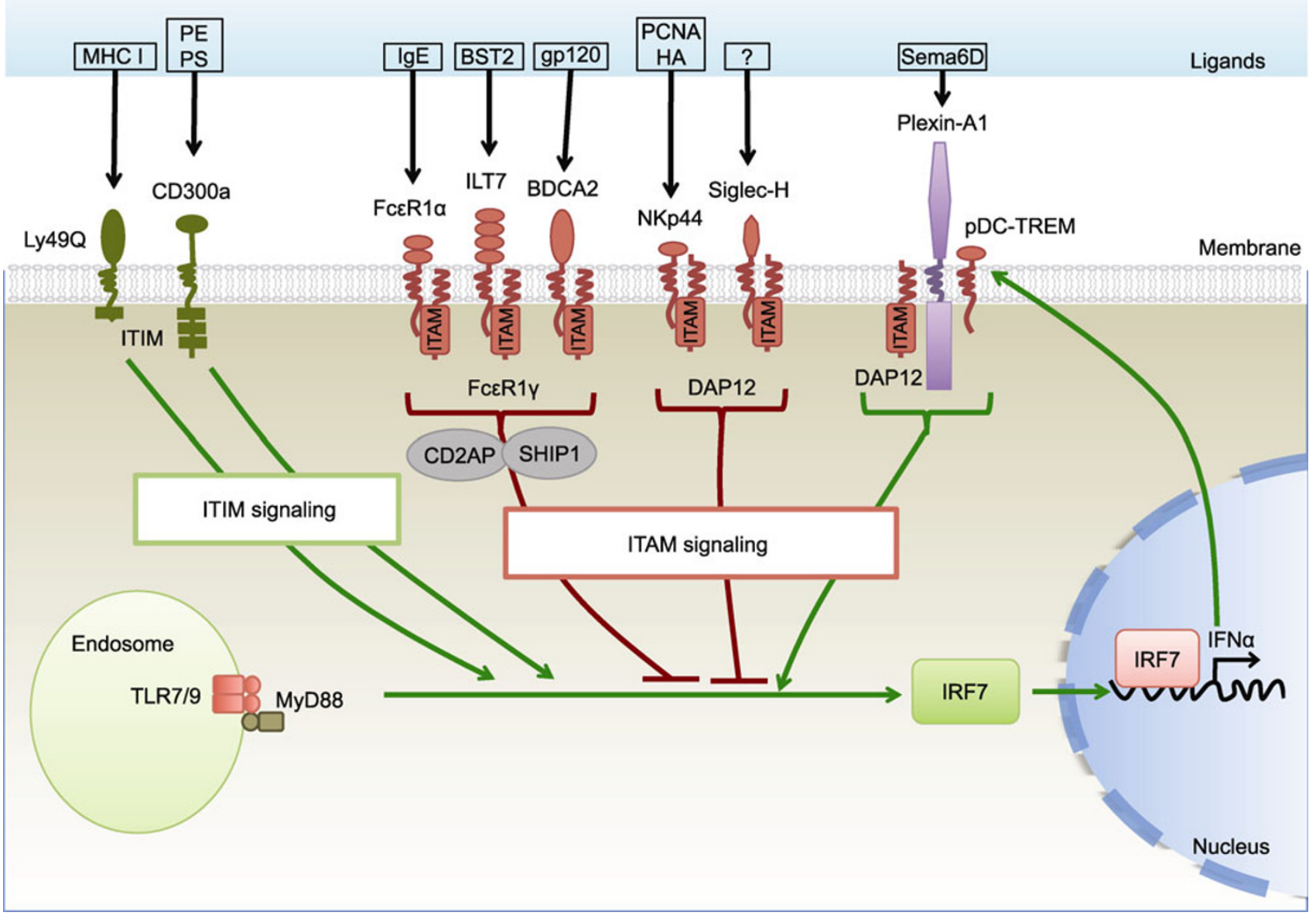

Figure 1. Regulation of TLR7/9 signaling by PDC surface receptors. PDCs express ITAM-associating or ITIM-containing receptors that play an important role in the TLR7/9-induced responses. Upon ligands engagement, TLR7/9 are activated and lead to IFN $\alpha$ secretion. Activation of the ITAM-associating receptors including FceR1 $\alpha$, ILT7, BDCA2, NKp44 and Siglec-H negatively regulates TLR7/9 signaling pathway, except pDC-TREM that is induced by IFN $\alpha$ and enhances TLR7/9 signaling. CD2AP and SHIP1 are essential components and are required for ITAM signaling pathways. In contrast, activation of ITIM-containing receptors like Ly49Q and CD300a positively regulate TLR7/9 signaling pathway.

dition, pDCs from DAP12-deficient mice lack surface Siglec-H expression and secrete more IFN in response to CpG DNA than do wild-type pDCs. Many Siglecs specifically recognize sialic acid-containing ligands. Nonetheless, although possessing all of the conserved structural features that contribute to sialic acid recognition, Siglec-H cannot bind sialic acid and the ligand for Siglec-H remains unknown (Blasius et al., 2006; Pillai et al., 2012).

In summary, pDC-receptors that associate with ITAMcontaining adaptors negatively regulate TLR7/9-induced response. However, PDC-TREM, a member of the triggering receptor expressed on myeloid cells family, is preferentially expressed on TLR-stimulated $\mathrm{pDCs}$ and directly associates with Plexin-A1 and DAP12. Sema6D, a ligand for Plexin-A1, directly binds to Plexin-A1 and induces robust production of type I IFN, which suggests that PDC-TREM/Plexin-
A1/DAP12 complex mediates positive signaling for type I IFN production by pDCs (Watarai et al., 2008) (Fig. 1). The molecular mechanisms for the contradictory effects mediated by DAP12 in pDCs need further investigation.

\section{VIRAL ITAM-CONTAINING PROTEINS}

Many virus-encoded proteins contain ITAMs, such as the K1 protein of human herpesvirus 8 ; the R1 protein in rhesus monkey rhadinovirus; latent membrane protein 2A (LMP2A) in Epstein-Barr virus; gp30 in bovine leukemia virus; and the envelope protein gp52 in murine mammary tumor virus (Lanier, 2006). The LMP2A has been shown to inhibit the IFN signaling pathway by targeting IFN receptor for degradation (Shah et al., 2009). However, whether the inhibition effects depend on the ITAMs in LMP2A needs further investigation. Since pDCs are the professional type I IFN producing cells, it 
will be of great value to study the functions of these viral ITAM-containing proteins in pDCs during viral infection.

For many ITAM-associated receptors, low-avidity interactions result in inhibitory consequences, whereas high-avidity interactions result in cell activation. A recent study shows that low avidity ligation of the ITAM-associated FcaRI results in the translocation of FcaRI and $\mathrm{SH} 2$ domain containing tyrosine phosphatase 1 (SHP1) to membrane lipid rafts. Subsequent ligation of activating receptors results in their colocalization with FcaRI and SHP1 and trafficking to an inhibitory intracellular compartment where signaling molecules are deactivated by SHP1 (Pfirsch-Maisonnas et al., 2011). Nevertheless, in pDCs, high-avidity interactions of ITAM-containing receptors lead to the attenuation of TLR-induced type I IFN production. So, how ITAM signaling is uniquely regulated in pDCs remains unknown.

\section{ITIMS-CONTAINING SURFACE RECEPTORS}

Classical ITIM is defined as a consensus of a six amino acid sequence, I/V/L/S- $x-Y-x x-L / V$, where $x$ denotes any amino acid. ITIMs present in the cytoplasmic domain of surface receptors with inhibitory properties which, when phosphorylated, recruit SHP1 and SHP2, or SHIP1. ITIMs have been found in a large number of inhibitory molecules from Ig superfamily and C-type lectin family (Daeron et al., 2008).

\section{CD300 GLYCOPROTEIN FAMILY}

The CD300 glycoprotein family members are type I transmembrane receptors with a single IgV-like extracellular domain. The transmembrane domains of CD300b, CD300c, CD300d, and CD300e contain a charged amino acid residue, which enables the association with the ITAM-containing adaptor DAP12, whereas the cytoplasmic domains of CD300a and CD300f contain ITIMs (Clark et al., 2009). In human pDCs, crosslinking of CD300a and CD300c with CMRF-35 antibody, which recognizes both molecules, inhibits HLA-DR expression and reduces TNFa and IL6 production while greatly enhances IRF7 expression and IFNa secretion by pDCs (Ju et al., 2008). Since CD300a contains ITIMs while CD300c associates with the ITAM-containing adaptor - DAP12, the function of CD300a and $\mathrm{CD} 300 \mathrm{c}$ in human pDCs needs further clarification. However, human pDCs highly express CD300a and but only have low-level expression of CD300c (unpublished observation). Crosslinking of both CD300a and CD300c may preferentially trigger the ITIM signaling pathway. Recent studies show that CD300a binds to phosphatidylethanolamine and phosphatidylserine, two phospholipids that are exposed on the outer leaflet of the plasma membrane of dead cells (Nakahashi-Oda et al., 2012; Simhadri et al., 2012). The functions of these two phospholipids and their receptor CD300a in pDCs need to be further identified.
Ly49Q

Ly49Q is an ITIM-containing surface receptor and has been shown to be involved in the regulation of the TLR7/9 signaling pathway. Ly49Q belongs to the C-type lectin natural killer receptor family and is expressed on mouse pDCs. Ly49Q interactions with class I MHC are necessary for IFNa secretion by $\mathrm{pDCs}$. Crosslinking of Ly49Q on mouse pDCs enhances TLR9-induced IFNa production (Fig. 1). Consistent with this, pDCs from Ly49Q knockout mice show severe defect in TLR9-dependent antiviral responses (Tai et al., 2008). Further study shows that Ly $49 Q$ colocalizes with CpG DNA in endolysosomal compartments and is necessary for the proper spatiotemporal regulation of intracellular trafficking of TLR9 (Yoshizaki et al., 2009).

Activation of ITIM will recruit SHP-1 or SHP-2 that play essential roles in TLR signaling pathways. Studies from knockout mice show that SHP-1 inhibits the production of proinflammatory cytokines but promotes the production of type I IFN in TLR3- and TLR4-mediated immune responses, whereas SHP-2 negatively regulates the TIR-domain-containing adapter-inducing IFN $\beta$ (TRIF) adaptor protein-dependent type I IFN and proinflammatory cytokine production (An et al., 2006, 2008). Interestingly, the bacteria translocated intimin receptor from enteropathogenic Escherichia coli also contains two ITIM-like regions that recruit host cell SHP-1 and inhibit the ubiquitination of TRAF6, which results in the suppression of the enteropathogenic Escherichia coli -stimulated expression of proinflammatory cytokines (Yan et al., 2012). However, the molecular mechanism of the ITIM signaling pathway and the roles of SHP-1 and SHP-2 in pDCs remain elusive.

\section{MOLECULES INVOLVED IN TLR7/9 PROCESSING AND TRAFFICKING}

TLR7/9 contain an extracellular leucine-rich repeat domain that is responsible for the recognition of ligands, a transmembrane domain and a cytoplasmic TIR domains that is required for initiating intracellular signaling. TLR7/9 reside in the endoplasmic reticulum (ER) in association with polytopic membrane protein UNC93B1 and heat shock protein gp96 (Yang et al., 2007; Kim et al., 2008). The UNC93B1 delivers TLR7/9 from the ER to endolysosomes, where the ectodomains of TLR7/9 are cleaved by cathepsins and asparagine endopeptidase to generate the functional receptors for ligand recognition (Ewald et al., 2008; Ewald et al., 2011). Heat shock protein gp96 regulates intracellular trafficking of TLR9 possibly through the proteolytic processing and conformational stability of TLR9 (Brooks et al., 2012).

In pDCs (Fig. 2), depending on the cellular location of the endosome, TLR7/9 activation leads to different responses, which suggests that a unique membrane trafficking pathway is required for endosomal TLR signaling in pDCs (Honda et al., 2005a; Guiducci et al., 2006). By using a genetic screen- 
ing method, adapter-related protein complex-3, biogenesis of lysosome-related organelle complexes (BLOC)-1, BLOC-2 and BLOC-3 and the solute carrier protein superfamily member Slc15a4 have been demonstrated to be required for pDCs to respond to nucleic acids through TLR7/9 (Blasius et al., 2010; Sasai et al., 2010). Recently, our group shows that phospholipid scramblase 1 (PLSCR1), an IFN-inducible protein that binds to the leucine-rich repeat domain of TLR9, is indispensable for type I IFN responses by regulating TLR9 trafficking to the endosomal compartment in pDCs (Talukder et al., 2012). Another pDC-specific adaptor molecule, protein kinase $C$ and casein kinase substrate in neurons 1 (PACSIN1), which has been shown to link membrane trafficking with the cytoskeleton and regulate the vesicle trafficking, plays a specific role in the type I IFN signaling cascade, which suggests that PACSIN1 may be also involved in TLR9 trafficking (Esashi et al., 2012).

\section{THE KEY ADAPTOR MOLECULE IN PDCS, MyD88}

MyD88 is an adaptor molecule contains an N-terminal death domain, a C-terminal TIR domain and linked by a short in-

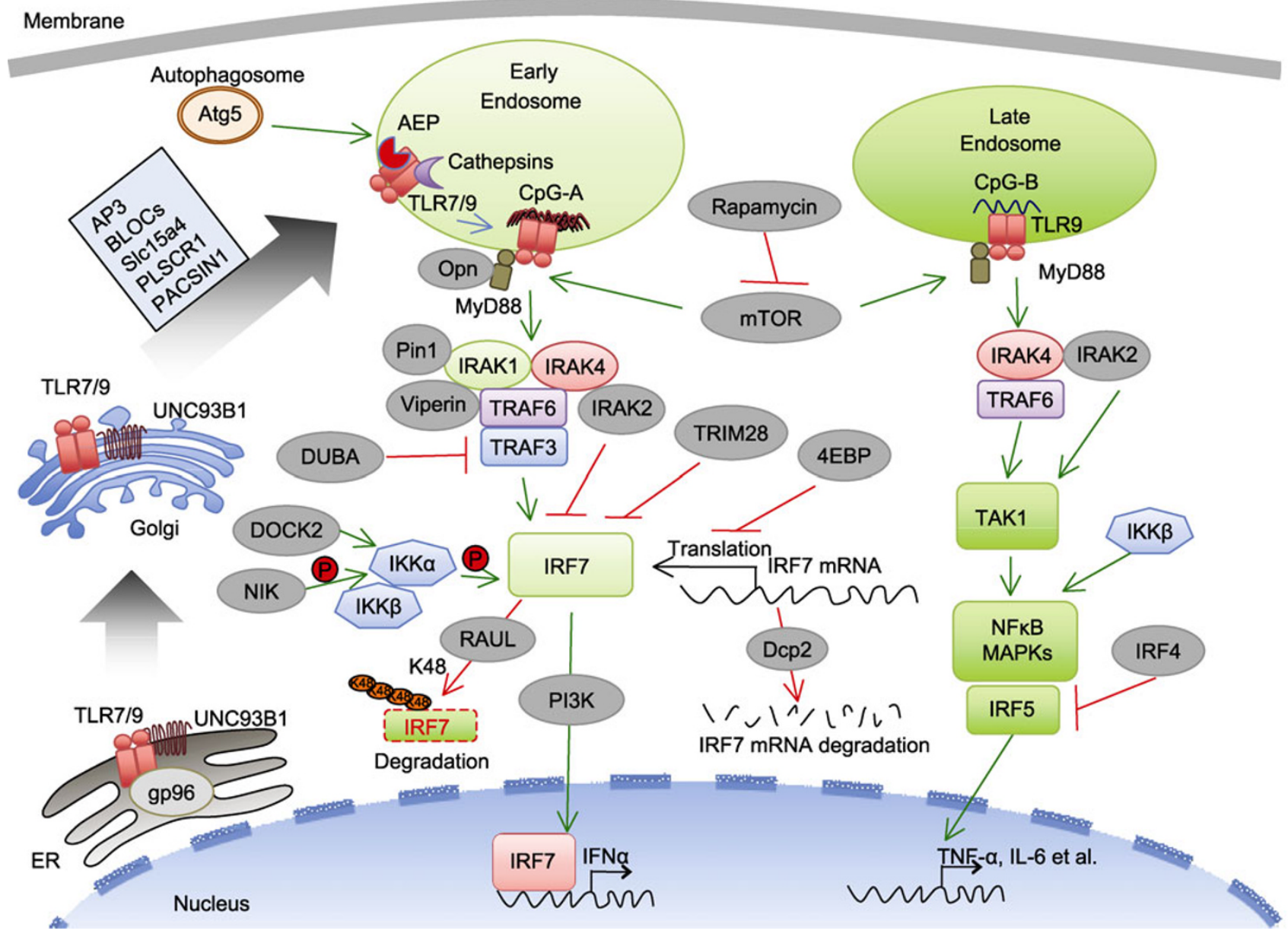

Figure 2. Regulation of the TLR7/9 signaling pathway in pDCs. In pDCs, TLR7 and TLR9 are synthesized in the endoplasmic reticulum (ER) and translocate from the ER to the endolysosome via UNC93B1. In the endolysosome, the ectodomains of TLR7/9 are cleaved by cathepsins and asparagine endopeptidase (AEP) to generate the functional receptors for ligand recognition. Following exposure to virus or nucleic acids, TLR7 and TLR9 in the endolysosome engage with their RNA or DNA agonists and induce different responses depend on the cellular localization. Molecules including Atg5, adapter-related protein complex-3 (AP3), BLOCs, SIc15a4, PLSCR1 and PACSIN1 are involved in the trafficking, splicing and modification of TLR7/9. In the early endosomes, a signalosome including IRAK4IRAK1- TRAF6- TRAF3 is formed, which leads to IRF7 activation and type I IFN production. Pin1, Viperin, osteopontin (Opn), DOCK2, $\mathrm{PI3K} /$ mammalian target of rapamycin (mTOR) complex, NF-KB inducing kinase (NIK) and IKKa/ $\beta$ positively regulate IRF7 activation by modifying the early endosome signalosome molecules. In contrast, deubiquitinating enzyme A (DUBA) negatively regulates type I IFN response through deubiquitination of TRAF3. While IRAK2, tripartite motif-containing 28 (TRIM28), 4EBPs, RAUL and Dcp2 play negatively roles by directly modifying IRF7. In the late endosomes, a signalosome including IRAK4- TRAF6- TAK1- NF-KB/MAPKs/IRF5 is formed and leads to proinflammatory cytokine production. MTOR complex and IKK $\beta$ are necessary for the proinflammatory cytokine induction. IRF4 negatively regulates proinflammatory cytokine production through IRF5. IRAK2 negatively regulates IFN production but positively regulates proinflammatory cytokine production in pDCs. 
termediate sequence. Previous studies have shown that MyD88 knockout mice do not respond to TLR7 and TLR9 ligands (Hacker et al., 2000; Schnare et al., 2000; Hemmi et al., 2002). These findings demonstrate that MyD88 is the key adaptor molecule in TLR7/9 signaling. Upon TLR7/9 activation, MyD88 is recruited to TLR7/9 through its TIR domain and functions as a bridging protein to recruit IL-1 receptor-associated kinase 4 (IRAK4) via its death domain, enabling IRAK4-induced downstream signaling (Kawai et al., 2004). Phosphatidylinositol-3 kinase / the mammalian target of rapamycin and the p70 ribosomal S6 protein kinase can regulate TLR9 signaling pathway possibly through stabilizing the interaction of TLR9 with the adaptor MyD88 (Cao et al., 2008). Osteopontin, a molecule that is induced in pDCs after stimulation with $\mathrm{CpG} D N A$, interacts with MyD88 and selectively enhances type I IFN response (Shinohara et al., 2006). Since MyD88 is the key adaptor for both NF-KB and IRF7 signaling pathway, it is still unclear how osteopontin specifically influences IRF7 signaling pathway but spares the NF-KB-dependent proinflammatory cytokines.

Several other molecules have been shown to regulate MyD88. Nrdp1, an E3 ubiquitin ligase, binds to MyD88 and TANK-binding kinase 1 and induces their lysine 48 (K48)-linked polyubiquitination, leading to reduced production of proinflammatory cytokines but increased IFN-production in TLR- activated macrophages (Wang et al., 2009). Sequestosome 1 and histone deacetylase 6 suppress the formation of the MyD88-TRAF6 complex through regulation of cylindromatosis 1 recruitment and limit activation of TLR-induced activation of p38 and JNK (Into et al., 2010). Flightless I homolog can interact with MyD88 and negatively regulate TLR4 signaling pathway; while its associated protein- LRRFIP2 (LRR Fli-l-interacting protein 2) and Flap-1 (Fli-I LRR-associated protein 1, or LRRFIP1) bind to MyD88 and positively regulate TLR-induced NF-KB activation (Dai et al., 2009). Since these studies are performed on non-pDC cells, the functions of these molecules in pDCs need further investigation.

\section{IRAK FAMILY MEMBERS}

IRAK family proteins include four members: IRAK1, IRAK2, IRAK4 and IRAK-M. IRAKs contain an N-terminal death domain and a central serine/threonine-kinase domain. Among these members, IRAK1 and IRAK4 have kinase activity, while IRAK2 and IRAK-M have no kinase activity. Upon TLR7/9 activation, IRAK4 is recruited to MyD88 through its death domain and activated. The activated IRAK4 interacts with and phosphorylates IRAK1, then IRAK4/IRAK1 complex dissociates from MyD88 and associates with TRAF6 to trigger downstream signaling pathway (Li et al., 2002; Lin et al., 2010). Studies from the knockout mice have revealed the importance of IRAK family in TLR signaling pathway. PDCs from IRAK4 knockout mice and IRAK4 kinase-inactive knock-in mice show impaired responses to TLR7/9 (Suzuki et al., 2002; Kawagoe et al., 2007; Kim et al., 2007). In IRAK1 deficiency pDCs, TLR7/9-induced type I IFN production is greatly impaired, whereas the proinflammatory cytokines production is normal (Uematsu et al., 2005). Study from IRAK2 knockout mice shows that IRAK2 is critical for sustaining the expression of proinflammatory cytokines in response to TLR stimulation, which indicates that IRAK2 is critical in late-phase TLR responses (Kawagoe et al., 2008). Recently, IRAK2 has been indicated to play a negative role in type I IFN response while play a positive role in proinflammatory cytokine production in pDCs (Wan et al., 2011). In contrast to IRAK1 and IRAK4 that are positive regulators of TLR7/9 signaling pathway, IRAK-M is induced upon TLR stimulation and negatively regulates TLR signaling by preventing the dissociation of IRAK1 and IRAK4 from MyD88 and the formation of IRAK1-TRAF6 complexes (Kobayashi et al., 2002).

One recent study shows that Viperin, a type I IFN inducible gene residing in the cytoplasmic lipid-enriched compartments in pDCs, interacts with IRAK1 and TRAF6 and facilitates the K63-linked ubiquitination of IRAK1, which finally leads to the nuclear translocation of IRF7 (Saitoh et al., 2011). The prolyl isomerase Pin1 accelerates the cis and trans conformations of phosphorylated Ser-Pro motifs, which controls the function of many key regulators in various cellular processes. Pin1 can be activated by TLR7 and TLR9, then binds to and acts on the phosphorylated Ser-Pro motifs in IRAK1. This resulted in activation of IRAK1 and facilitated its release from the MyD88 signaling complex to activate the transcription factor IRF7 and induce type I IFN (Tun-Kyi et al., 2011).

The E3 ubiquitin ligase family of Pellino proteins has been show to catalyze K63-linked polyubiquitination of IRAKs. Pellino family consists of three members: Pellino1, Pellino2 and Pellino3. Pellino3 is expressed in two spliced forms (Moynagh, 2009). The Pellino family member contains an $\mathrm{N}$-terminal forkhead-associated domain that mediates association with IRAKs, and a C-terminal RING-like domain that confers E3 ubiquitin ligase activity and an ability to catalyze K63-linked polyubiquitination of IRAKs. Pellino members have been shown to be important mediators in TLR signaling pathway that leads to the activation of NF-KB and MAPKs as well as IFN production (Enesa et al., 2012). The physiological roles of Pellino members in pDCs remain to be defined.

\section{TRAF FAMILY MEMBERS}

TRAF family contains 7 members. Except TRAF7, all TRAFs contain a TRAF domain on their C-terminal, and an $\mathrm{N}$-terminal RING finger domain and zinc finger domains (with the exception of TRAF1 that lacks zinc finger domains). TRAF family members are intracellular signaling molecules with crucial functions in the signal transduction pathways initiated by TLR7/9 (Hacker et al., 2011). TRAF6 is essential for the activation of TLR7/9 signaling pathways, including NF-KB/MAPKs and IRF7 pathways. TRAF6 functions to- 
gether with the E2 enzyme complex Ubc13/Uev1A to catalyze the K63-linked polyubiquitin of IRF7, which leads to type I IFN production. TRAF6 also activates TAK1 in an ubiquitin-dependent manner. TAK1 is a member of the MAP kinase kinase kinase family. Once activated by TRAF6, TAK1 leads to the activation of NF-KB and MAPKs (Ninomiya-Tsuji et al., 1999; Deng et al., 2000). By contrast, TRAF3 has been demonstrated to play a key role in type I IFN production and the anti-inflammatory cytokine IL-10, but is dispensable for the induction of proinflammatory cytokines (Hacker et al., 2006; Oganesyan et al., 2006). TRAF4 has been shown to associate with $\mathrm{p} 47^{\text {phox }}$, a subunit of the cytosolic NADPH oxidase complex, and plays a negative role in TLR-induced responses through interaction with TRAF6 and TRIF (Takeshita et al., 2005). TRAF1 associates with TRIF and negatively regulates TLR3-induced signaling (Su et al., 2006). The exact roles of TRAF1 and TRAF4 in pDCs need further investigation.

Deubiquitinating enzyme $A$, an ovarian tumor domain-containing deubiquitinating enzyme, negative regulates of type I IFN responses by selectively cleaving the K63-linked polyubiquitin chains on TRAF3, resulting in its dissociation from the downstream signaling complex (Kayagaki et al., 2007). During virus infection with vesicular stomatitis virus or Sendai virus, the ubiquitin ligase TRIAD3A (also known as RNF216 isoform 1) removes the K63-linked ubiquitin chains from TRAF3 and enhances the K48-linked ubiquitylation, which leads to the proteasomal degradation of TRAF3 and, ultimately, results in the termination of the type I IFN response (Nakhaei et al., 2009).

\section{IRF FAMILY MEMBERS}

IRFs constitute a family of transcription factors that commonly possess a novel helix-turn-helix DNA-binding motif. So far, 9 family members have been identified, IRF1 to IRF9. IRF3 and IRF7 are closely related in terms of their primary structures (Taniguchi et al., 2001). However, studies from knockout mice have revealed that IRF7 but not IRF3 is master regulator of type I IFN in pDCs. In response to TLR9 ligand, pDCs from IRF7 knockout mice do not produce type I IFN, while produce normal level of proinflammatory cytokines (Honda et al., 2005b). In contrary, pDCs from IRF5 knockout mice produce normal level of type I IFN, but do not produce proinflammatory cytokines in response to TLR9 ligand. This study suggests that IRF5 plays key roles in the activation of genes for proinflammatory cytokines (Takaoka et al., 2005). PDCs from IFN $\alpha$ receptor (IFNAR) knockout mice showed greatly reduced type I IFN production, which suggests pDCs are entirely dependent on IFNAR feedback for type I IFN production. IRF8 plays a significant role in magnifying the second phase of IFN transcription by prolonging binding of basic transcription machinery to the IFN promoters and also contributes to pDC development (Tsujimura et al., 2003; Tamura et al., 2005; Tailor et al., 2007). IRF9 associates with activated STAT1 and STAT2 to form the multimeric transcription factor - interferon-stimulated gene factor 3 that initiates the transcription of the IFN-stimulated genes including IRF7; in consistent with this, pDCs from IRF9 knockout mice do not produce type I IFN (Horvath et al., 1996; Sato et al., 1998). In contrast to the positive roles of IRF3, IRF5, IRF7, IRF8 and IRF9, IRF2 and IRF4 play negative roles in TLR7/9 signaling. IRF2 functions as a negative regulator by antagonizing the type I IFN induced interferon-stimulated gene factor 3 (Hida et al., 2000). IRF4 selectively inhibits IRF5-dependent proinflammatory genes through competing with IRF5 for MyD88 interaction in a cell type specific manner (Negishi et al., 2005).

\section{MOLECULES INVOLVED IN IRF7 MODIFICATION, ACTIVATION AND DEGRADATION}

PDCs constitutively express high levels of IRF7, which is the mater regulator of type I IFN production (Honda et al., 2005b). It has been shown that constitutive activation of NF-KB p65/p50 and p38 contribute to the high expression level of IRF7 in pDCs (Osawa et al., 2006). In response to TLR9 ligand, IRF7 is activated and translocated from the cytosol to the nuclear to induce type I IFN production. IRF7 has been shown to be a substrate of TRAF6, which catalyzes K63-linked polyubiquitination of IRF7 in its C-terminal lysine sites that is necessary for IRF7 activation (Ning et al., 2008). The translational repressors 4EBP1 and 4EBP2 can negative regulate type I IFN production via translational repression of IRF7 mRNA, while the mammalian Dcp2 mRNA-decapping protein promotes IRF7 mRNA degradation (Colina et al., 2008; Li et al., 2012). The tripartite motif-containing protein 28 binds to IRF7 and increases its SUMOylation specifically, which results in transcriptional repression and subsequent impaired type I IFN production (Liang et al., 2011). The ubiquitin E3 ligase RAUL also negatively regulates type I IFN through directly catalyzing K48-linked polyubiquitination of IRF7 followed by IRF7 proteasome-dependent degradation (Yu and Hayward, 2010). IRF7 binds to its own promoter to auto-regulate IRF7 gene expression. The transcription factor FOXO3 forms a complex with nuclear co-repressor 2 and histone deacetylase 3, binds to the IRF7 promoter and negatively regulates of IRF7 gene expression. Upon type I IFN stimulation, the transcription of IRF7 is induced and the $\mathrm{PI} 3 \mathrm{~K} / \mathrm{Akt}$ pathway is also activated, which in turn induces FOXO3 degradation. This leads to the high level of IRF7 that is essential for the maximal antiviral response (Litvak et al., 2012).

Several other molecules have also been reported to modify IRF7 activity. TRIF can associate with and activate IRF7 through TANK binding kinase 1 and its downstream kinases (Han et al., 2004). PIASy, a member of the PIAS SUMO-ligase family, inhibits IRF7 activity (Zhang et al., 2004). TRIM21 (also known as Ro52), an IFN-inducible E3 ubiquitin ligase, interacts with and ubiquitinates IRF7, which results in 
results in the degradation of IRF7 (Higgs et al., 2010). One recent study shows that the E3 ubiquitin ligase Pellino3 is induced by TLR3, interacts with and ubiquitinates TRAF6, which negatively regulates the ubiquitination of IRF7, resulting in down-regulation of type I IFN expression (Siednienko et al., 2012). Their roles in TLR7/9-induced responses in pDCs need further studies.

\section{IKK FAMILY MEMBERS}

The IKK complex is the central regulator of the NF-KB signaling. IKK complex contains two kinases (IKKa and IKK $\beta$ ) and a regulatory subunit, IKKY/ NEMO. IKKa and IKK $\beta$ show a similar structure, which include an amino-terminal kinase domain, a helix-loop-helix domain that functions in modulating IKK kinase activity, and a leucine zipper domain that allows homo- or heterodimerization of the kinases (Israel, 2010). It has been shown that pDCs from IKKa knockout mice show selectively defects in TLR7/9-induced IFNa induction, which suggests that IKKa is a key regulator in pDCs. IKKa associates with and phosphorylates IRF7 to induce type I IFN response (Hoshino et al., 2006). NF-kB inducing kinase acts as an upstream kinase of IKKa in activation of IRF3/7 and may play important role in TLR7/9-mediated type I IFN production (Wang et al., 2008). Inhibiting IKK $\beta$ activity by using IKK $\beta$-specific inhibitors or by siRNA knockdown of IKK $\beta$ also result in reduced TLR7/9-induced IFN and proinflammatory cytokine production (Pauls et al., 2012). These studies show that IKK family members play essential roles in TLR7/9-mediated signaling pathways.

DOCK2, an atypical Rac activator, controls IKKa activation and specifically regulate TLR7/9-induced type I IFN induction (Gotoh et al., 2010). Regnase-1 (Zc3h12a), an RNase that is essential for controlling immune responses by destabilizing mRNA including IL6, IL12 and the calcitonin receptor gene, has been shown to be the target of IKK complex. In response to TLR, regnase-1 is phosphorylated by IKK complex and IRAK1. The phosphorylated regnase-1 undergoes ubiquitination and degradation, which results in enhance IL6 and IL12 mRNA expression (Matsushita et al., 2009; Iwasaki et al., 2011).

\section{E2-2, THE KEY TRANSCRIPTIONAL REGULATOR OF PDCS}

E proteins comprise a family of basic helix-loop-helix transcription factors. E proteins include E12 and E47, HEB and E2-2, which form homodimers or heterodimers with other family members. E2-2 (also known as TCF4) is a member of E proteins that is preferentially expressed in pDCs. E2-2 directly activates multiple pDC-enriched genes, including transcription factors involved in pDC development (SpiB, IRF8) and function (IRF7). Deletion of murine E2-2 specifically blocks the development of $\mathrm{pDCs}$ and abolishes IFN response to CpG DNA. In addition, deletion of transcription factor E2-2 from mature peripheral pDCs caused their spontaneous differentiation into cells with classical dendritic cells properties, including morphological changes, enhanced T cell priming capacity and upregulated classical dendritic cell-enriched genes. These studies suggest that E2-2 is the key specific transcriptional regulator of $\mathrm{pDC}$ development and of the pDC-mediated IFN response (Cisse et al., 2008; Nagasawa et al., 2008; Ghosh et al., 2010).

\section{AUTOPHAGY-RELATED PROTEINS}

Autophagy plays critical roles in maintaining cellular energy homeostasis and the cell adaptation to environmental stresses during starvation, stress and infection. Recent studies have shown that autophagy plays important roles in antiviral immune responses (Saitoh and Akira, 2010). The autophagy-related gene (Atg) 5-Atg12 conjugate, a key regulator of the autophagic process, associates with retinoic acid-inducible gene I and IFN $\beta$ promoter stimulator 1 and negatively regulates type I IFN production in mouse embryonic fibroblasts in response to vesicular stomatitis virus infection (Jounai et al., 2007). Also, loss of Atg16L1, an essential component of the autophagic machinery that forms a complex with Atg5-Atg12, results in enhanced production of proinflammatory cytokines in response to TLR4, TLR7 and TLR9 ligands in mouse macrophages (Jounai et al., 2007). In addition, Atg5 and Atg7 that is required for the conjugation of Atg12 with Atg5 have been demonstrated to negatively regulate type I IFN production in mouse embryonic fibroblasts and macrophages (Jounai et al., 2007; Tal et al., 2009).

In contrast to the inhibitory effects of autophagy in other cell types, pDCs from Atg5 knockout mice show impaired type I IFN and IL12 p40 production in response to RNA virus infection, which indicates autophagy plays a positive role in pDCs (Lee et al., 2007). PDCs constitutively contain autophagosomes that are necessary for the TLR7-dependent induction of innate immune responses. However, in response to TLR9 ligands, CpG DNA and herpes simplex virus 1, pDCs from Atg5 knockout mice show impaired type I IFN but normal level of IL12 p40 (Lee et al., 2007). This study indicates that, although TLR7 and TLR9 share the signaling pathway that induces type I IFN, TLR7 and TLR9 may be different regulated to induce inflammatory cytokine production in response to their ligands.

\section{FUTURE PERSPECTIVES}

Despite the extensive studies during the past decade, the components of TLR7/9 signaling network remain elusive, especially in pDCs. The following questions are outstanding, including: (1) How do ITAM and ITIM signaling intersect with TLR7/9 signaling? (2) What are the natural ligands for $\mathrm{pDC}$ receptors, such as BDCA2 and Siglec-H? (3) What are the molecular mechanisms underlying the specialization of TLR9-mediated early endosomal IFN responses versus late 
endosomal proinflammatory cytokine responses?

Because of the rareness of pDCs, it has been very difficult to study the signaling network in pDCs. Many new approaches have been used to study the signaling complex: (1) The pDC yeast-two hybrid library, by which we have identified PLSCR1 as a TLR9 binding molecules, will help us to identify the pDC-specific TLR7/9 signaling molecules. (2) The integrative strategy combining transcriptomics, genetic and chemical perturbations, and unbiased phosphoproteomics will facilitate the deciphering of the pDC-specific signaling network. By using this method, Polo-like kinases 2 and 4 have been identified to be essential components of antiviral signaling in pDCs (Chevrier et al., 2011). (3) The global proteomic analysis will help us to map a dynamic protein interactome network (Li et al., 2011). (4) The forward genetic approach to identify genes like AP-3, Slc15a4 and BLOC that are essential for pDC functions (Blasius et al., 2010).

PDCs are professional type I IFN producing cells and play key roles in innate and adaptive immune responses. Deciphering the unique signaling networks in pDCs that contribute to the rapid and massive amount of type I IFN production in response to viral infection will be of great help in better manipulating immune responses associated with viral infection, autoimmune diseases, cancers and vaccines.

\section{ACKNOWLEDGEMENTS}

We thank Carson Harrod and Luann T Snipes for critical reading of the manuscript.

\section{ABBREVIATIONS}

Atg, autophagy-related gene; BDCA2, blood dendritic cell antigen 2; BLOC, biogenesis of lysosome-related organelle complex; CD2AP, CD2 associated adaptor protein; DAP12, DNAX activation protein 12; IFN, interferon; IKK, IKB kinase; IL, interleukin; ILT, immunoglobulin-like transcript; IRAK, IL-1 receptor-associated kinases; IRF, interferon regulatory factor; ITAM, immunoreceptor tyrosine-based activation motif; ITIM, immunoreceptor tyrosine-based inhibitory motif; LILR, leukocyte Ig-like receptor; MAPKs, mitogen-activated protein kinases; PACSIN1, protein kinase $C$ and casein kinase substrate in neurons 1; pDCs, plasmacytoid dendritic cells; PLSCR1, phospholipid scramblase 1; PRRs, pattern recognition receptors; SHIP1, $\mathrm{SH} 2$-containing inositol phosphatase-1; SHP-1, SH2 domain containing tyrosine phosphatase 1 ; TAK1, transforming growth factor- $\beta$-activated protein kinase 1 ; TIR, Toll/IL1 receptor; TLR, Toll-like receptor; TRAF, TNF receptor-associated factor; TRIF, TIR-domain-containing adapter-inducing IFN $\beta$

\section{REFERENCES}

Akira, S., and Takeda, K. (2004). Toll-like receptor signalling. Nat Rev Immunol 4, 499-511.

An, H., Hou, J., Zhou, J., Zhao, W., Xu, H., Zheng, Y., Yu, Y., Liu, S., and Cao, X. (2008). Phosphatase SHP-1 promotes TLR- and RIG-I-activated production of type I interferon by inhibiting the kinase IRAK1. Nat Immunol 9, 542-550.

An, H., Zhao, W., Hou, J., Zhang, Y., Xie, Y., Zheng, Y., Xu, H., Qian,
C., Zhou, J., Yu, Y., et al. (2006). SHP-2 phosphatase negatively regulates the TRIF adaptor protein-dependent type I interferon and proinflammatory cytokine production. Immunity 25, 919-928.

Arnon, T.I., Lev, M., Katz, G., Chernobrov, Y., Porgador, A., and Mandelboim, O. (2001). Recognition of viral hemagglutinins by NKp44 but not by NKp30. Eur J Immunol 31, 2680-2689.

Bao, M., Hanabuchi, S., Facchinetti, V., Du, Q., Bover, L., Plumas, J., Chaperot, L., Cao, W., Qin, J., Sun, S.C., et al. (2012). CD2AP/SHIP1 complex positively regulates plasmacytoid dendritic cell receptor signaling by inhibiting the E3 ubiquitin ligase Cbl. J Immunol 189, 786-792.

Blasius, A.L., Arnold, C.N., Georgel, P., Rutschmann, S., Xia, Y., Lin, P., Ross, C., Li, X., Smart, N.G., and Beutler, B. (2010). Slc15a4, AP-3, and Hermansky-Pudlak syndrome proteins are required for Toll-like receptor signaling in plasmacytoid dendritic cells. Proc Natl Acad Sci U S A 107, 19973-19978.

Blasius, A.L., Cella, M., Maldonado, J., Takai, T., and Colonna, M. (2006). Siglec-H is an IPC-specific receptor that modulates type I IFN secretion through DAP12. Blood 107, 2474-2476.

Bonaccorsi, I., Cantoni, C., Carrega, P., Oliveri, D., Lui, G., Conte, R., Navarra, M., Cavaliere, R., Traggiai, E., Gattorno, M., et al. (2010). The immune inhibitory receptor LAIR-1 is highly expressed by plasmacytoid dendritic cells and acts complementary with NKp44 to control IFNalpha production. PLoS One 5, e15080.

Brooks, J.C., Sun, W., Chiosis, G., and Leifer, C.A. (2012). Heat shock protein gp96 regulates Toll-like receptor 9 proteolytic processing and conformational stability. Biochem Biophys Res Commun 421, 780-784.

Brown, D., Trowsdale, J., and Allen, R. (2004). The LILR family: modulators of innate and adaptive immune pathways in health and disease. Tissue Antigens 64, 215-225.

Cao, W., Bover, L., Cho, M., Wen, X., Hanabuchi, S., Bao, M., Rosen, D.B., Wang, Y.H., Shaw, J.L., Du, Q., et al. (2009). Regulation of TLR7/9 responses in plasmacytoid dendritic cells by BST2 and ILT7 receptor interaction. J Exp Med 206, 1603-1614.

Cao, W., Manicassamy, S., Tang, H., Kasturi, S.P., Pirani, A., Murthy, N., and Pulendran, B. (2008). Toll-like receptor-mediated induction of type I interferon in plasmacytoid dendritic cells requires the rapamycin-sensitive $\mathrm{PI}(3) \mathrm{K}-\mathrm{mTOR}-\mathrm{p} 70$ S6K pathway. Nat Immunol 9, 1157-1164.

Cao, W., Rosen, D.B., Ito, T., Bover, L., Bao, M., Watanabe, G., Yao, Z., Zhang, L., Lanier, L.L., and Liu, Y.J. (2006). Plasmacytoid dendritic cell-specific receptor ILT7-Fc epsilonRI gamma inhibits Toll-like receptor-induced interferon production. J Exp Med 203, 1399-1405.

Cao, W., Zhang, L., Rosen, D.B., Bover, L., Watanabe, G., Bao, M., Lanier, L.L., and Liu, Y.J. (2007). BDCA2/Fc epsilon RI gamma complex signals through a novel BCR-like pathway in human plasmacytoid dendritic cells. PLoS Biol 5, e248.

Chevrier, N., Mertins, P., Artyomov, M.N., Shalek, A.K., lannacone, M., Ciaccio, M.F., Gat-Viks, I., Tonti, E., DeGrace, M.M., Clauser, K.R., et al. (2011). Systematic discovery of TLR signaling components delineates viral-sensing circuits. Cell 147, 853-867.

Cisse, B., Caton, M.L., Lehner, M., Maeda, T., Scheu, S., Locksley, R., Holmberg, D., Zweier, C., den Hollander, N.S., Kant, S.G., et al. (2008). Transcription factor E2-2 is an essential and specific regulator of plasmacytoid dendritic cell development. Cell 135, $37-48$. 
Clark, G.J., Ju, X., Tate, C., and Hart, D.N. (2009). The CD300 family of molecules are evolutionarily significant regulators of leukocyte functions. Trends Immunol 30, 209-217.

Colina, R., Costa-Mattioli, M., Dowling, R.J., Jaramillo, M., Tai, L.H., Breitbach, C.J., Martineau, Y., Larsson, O., Rong, L., Svitkin, Y.V., et al. (2008). Translational control of the innate immune response through IRF-7. Nature 452, 323-328.

Daeron, M., Jaeger, S., Du Pasquier, L., and Vivier, E. (2008). Immunoreceptor tyrosine-based inhibition motifs: a quest in the past and future. Immunol Rev 224, 11-43.

Dai, P., Jeong, S.Y., Yu, Y., Leng, T., Wu, W., Xie, L., and Chen, X. (2009). Modulation of TLR signaling by multiple MyD88-interacting partners including leucine-rich repeat Fli-l-interacting proteins. J Immunol 182, 3450-3460.

Deng, L., Wang, C., Spencer, E., Yang, L., Braun, A., You, J., Slaughter, C., Pickart, C., and Chen, Z.J. (2000). Activation of the IkappaB kinase complex by TRAF6 requires a dimeric ubiquitin-conjugating enzyme complex and a unique polyubiquitin chain. Cell 103, 351-361.

Dikic, I. (2002). CIN85/CMS family of adaptor molecules. FEBS Lett 529, 110-115.

Enesa, K., Ordureau, A., Smith, H., Barford, D., Cheung, P.C., Patterson-Kane, J., Arthur, J.S., and Cohen, P. (2012). Pellino1 Is Required for Interferon Production by Viral Double-stranded RNA. J Biol Chem 287, 34825-34835.

Esashi, E., Bao, M., Wang, Y.H., Cao, W., and Liu, Y.J. (2012). PACSIN1 regulates the TLR7/9-mediated type I interferon response in plasmacytoid dendritic cells. Eur J Immunol 42, 573-579.

Ewald, S.E., Engel, A., Lee, J., Wang, M., Bogyo, M., and Barton, G.M. (2011). Nucleic acid recognition by Toll-like receptors is coupled to stepwise processing by cathepsins and asparagine endopeptidase. J Exp Med 208, 643-651.

Ewald, S.E., Lee, B.L., Lau, L., Wickliffe, K.E., Shi, G.P., Chapman, H.A., and Barton, G.M. (2008). The ectodomain of Toll-like receptor 9 is cleaved to generate a functional receptor. Nature 456, 658-662.

Fuchs, A., Cella, M., Kondo, T., and Colonna, M. (2005). Paradoxic inhibition of human natural interferon-producing cells by the activating receptor NKp44. Blood 106, 2076-2082.

Ghosh, H.S., Cisse, B., Bunin, A., Lewis, K.L., and Reizis, B. (2010). Continuous expression of the transcription factor e2-2 maintains the cell fate of mature plasmacytoid dendritic cells. Immunity 33 , 905-916.

Gilliet, M., Cao, W., and Liu, Y.J. (2008). Plasmacytoid dendritic cells: sensing nucleic acids in viral infection and autoimmune diseases. Nat Rev Immunol 8, 594-606.

Gotoh, K., Tanaka, Y., Nishikimi, A., Nakamura, R., Yamada, H., Maeda, N., Ishikawa, T., Hoshino, K., Uruno, T., Cao, Q., et al. (2010). Selective control of type I IFN induction by the Rac activator DOCK2 during TLR-mediated plasmacytoid dendritic cell activation. J Exp Med 207, 721-730.

Guiducci, C., Ott, G., Chan, J.H., Damon, E., Calacsan, C., Matray, T., Lee, K.D., Coffman, R.L., and Barrat, F.J. (2006). Properties regulating the nature of the plasmacytoid dendritic cell response to Toll-like receptor 9 activation. J Exp Med 203, 1999-2008.

Hacker, H., Redecke, V., Blagoev, B., Kratchmarova, I., Hsu, L.C.,
Wang, G.G., Kamps, M.P., Raz, E., Wagner, H., Hacker, G., et al. (2006). Specificity in Toll-like receptor signalling through distinct effector functions of TRAF3 and TRAF6. Nature 439, 204-207.

Hacker, H., Tseng, P.H., and Karin, M. (2011). Expanding TRAF function: TRAF3 as a tri-faced immune regulator. Nat Rev Immunol 11, 457-468.

Hacker, H., Vabulas, R.M., Takeuchi, O., Hoshino, K., Akira, S., and Wagner, H. (2000). Immune cell activation by bacterial CpG-DNA through myeloid differentiation marker 88 and tumor necrosis factor receptor-associated factor (TRAF)6. J Exp Med 192, 595-600.

Hamerman, J.A., and Lanier, L.L. (2006). Inhibition of immune responses by ITAM-bearing receptors. Sci STKE 2006, re1.

Han, K.J., Su, X., Xu, L.G., Bin, L.H., Zhang, J., and Shu, H.B. (2004). Mechanisms of the TRIF-induced interferon-stimulated response element and NF-kappaB activation and apoptosis pathways. J Biol Chem 279, 15652-15661.

Hemmi, H., Kaisho, T., Takeuchi, O., Sato, S., Sanjo, H., Hoshino, K., Horiuchi, T., Tomizawa, H., Takeda, K., and Akira, S. (2002). Small anti-viral compounds activate immune cells via the TLR7 MyD88-dependent signaling pathway. Nat Immunol 3, 196-200.

Hida, S., Ogasawara, K., Sato, K., Abe, M., Takayanagi, H., Yokochi, T., Sato, T., Hirose, S., Shirai, T., Taki, S., et al. (2000). CD8(+) T cell-mediated skin disease in mice lacking IRF-2, the transcriptional attenuator of interferon-alpha/beta signaling. Immunity 13, 643-655.

Higgs, R., Lazzari, E., Wynne, C., Ni Gabhann, J., Espinosa, A., Wahren-Herlenius, M., and Jefferies, C.A. (2010). Self protection from anti-viral responses--Ro52 promotes degradation of the transcription factor IRF7 downstream of the viral Toll-Like receptors. PLoS One 5, e11776.

Honda, K., Ohba, Y., Yanai, H., Negishi, H., Mizutani, T., Takaoka, A., Taya, C., and Taniguchi, T. (2005a). Spatiotemporal regulation of MyD88-IRF-7 signalling for robust type-I interferon induction. Nature 434, 1035-1040.

Honda, K., Yanai, H., Negishi, H., Asagiri, M., Sato, M., Mizutani, T., Shimada, N., Ohba, Y., Takaoka, A., Yoshida, N., et al. (2005b). IRF-7 is the master regulator of type-I interferon-dependent immune responses. Nature 434, 772-777.

Horvath, C.M., Stark, G.R., Kerr, I.M., and Darnell, J.E., Jr. (1996). Interactions between STAT and non-STAT proteins in the interferon-stimulated gene factor 3 transcription complex. Mol Cell Biol 16, 6957-6964.

Hoshino, K., Sugiyama, T., Matsumoto, M., Tanaka, T., Saito, M., Hemmi, H., Ohara, O., Akira, S., and Kaisho, T. (2006). IkappaB kinase-alpha is critical for interferon-alpha production induced by Toll-like receptors 7 and 9. Nature 440, 949-953.

Into, T., Inomata, M., Niida, S., Murakami, Y., and Shibata, K. (2010). Regulation of MyD88 aggregation and the MyD88-dependent signaling pathway by sequestosome 1 and histone deacetylase 6 . J Biol Chem 285, 35759-35769.

Israel, A. (2010). The IKK complex, a central regulator of NF-kappaB activation. Cold Spring Harb Perspect Biol 2, a000158.

Ivashkiv, L.B. (2011). How ITAMs inhibit signaling. Sci Signal 4, pe20.

Iwasaki, H., Takeuchi, O., Teraguchi, S., Matsushita, K., Uehata, T., Kuniyoshi, K., Satoh, T., Saitoh, T., Matsushita, M., Standley, 
D.M., et al. (2011). The IkappaB kinase complex regulates the stability of cytokine-encoding mRNA induced by TLR-IL-1R by controlling degradation of regnase-1. Nat Immunol 12, 1167-1175.

Jounai, N., Takeshita, F., Kobiyama, K., Sawano, A., Miyawaki, A., Xin, K.Q., Ishii, K.J., Kawai, T., Akira, S., Suzuki, K., et al. (2007). The Atg5 Atg12 conjugate associates with innate antiviral immune responses. Proc Natl Acad Sci U S A 104, 14050-14055.

Ju, X., Zenke, M., Hart, D.N., and Clark, G.J. (2008). CD300a/c regulate type I interferon and TNF-alpha secretion by human plasmacytoid dendritic cells stimulated with TLR7 and TLR9 ligands. Blood 112, 1184-1194.

Kadowaki, N., Ho, S., Antonenko, S., Malefyt, R.W., Kastelein, R.A., Bazan, F., and Liu, Y.J. (2001). Subsets of human dendritic cell precursors express different toll-like receptors and respond to different microbial antigens. J Exp Med 194, 863-869.

Kawagoe, T., Sato, S., Jung, A., Yamamoto, M., Matsui, K., Kato, H., Uematsu, S., Takeuchi, O., and Akira, S. (2007). Essential role of IRAK-4 protein and its kinase activity in Toll-like receptor-mediated immune responses but not in TCR signaling. $J$ Exp Med 204, 1013-1024.

Kawagoe, T., Sato, S., Matsushita, K., Kato, H., Matsui, K., Kumagai, Y., Saitoh, T., Kawai, T., Takeuchi, O., and Akira, S. (2008). Sequential control of Toll-like receptor-dependent responses by IRAK1 and IRAK2. Nat Immunol 9, 684-691.

Kawai, T., Sato, S., Ishii, K.J., Coban, C., Hemmi, H., Yamamoto, M., Terai, K., Matsuda, M., Inoue, J., Uematsu, S., et al. (2004). Interferon-alpha induction through Toll-like receptors involves a direct interaction of IRF7 with MyD88 and TRAF6. Nat Immunol 5, 1061-1068.

Kayagaki, N., Phung, Q., Chan, S., Chaudhari, R., Quan, C., O'Rourke, K.M., Eby, M., Pietras, E., Cheng, G., Bazan, J.F., et al. (2007). DUBA: a deubiquitinase that regulates type I interferon production. Science 318, 1628-1632.

Kim, T.W., Staschke, K., Bulek, K., Yao, J., Peters, K., Oh, K.H., Vandenburg, Y., Xiao, H., Qian, W., Hamilton, T., et al. (2007). A critical role for IRAK4 kinase activity in Toll-like receptor-mediated innate immunity. J Exp Med 204, 1025-1036.

Kim, Y.M., Brinkmann, M.M., Paquet, M.E., and Ploegh, H.L. (2008). UNC93B1 delivers nucleotide-sensing toll-like receptors to endolysosomes. Nature 452, 234-238.

Kobayashi, K., Hernandez, L.D., Galan, J.E., Janeway, C.A., Jr., Medzhitov, R., and Flavell, R.A. (2002). IRAK-M is a negative regulator of Toll-like receptor signaling. Cell 110, 191-202.

Lanier, L.L. (2006). Viral immunoreceptor tyrosine-based activation motif (ITAM)-mediated signaling in cell transformation and cancer. Trends Cell Biol 16, 388-390.

Lee, H.K., Lund, J.M., Ramanathan, B., Mizushima, N., and Iwasaki, A. (2007). Autophagy-dependent viral recognition by plasmacytoid dendritic cells. Science 315, 1398-1401.

Li, S., Strelow, A., Fontana, E.J., and Wesche, H. (2002). IRAK-4: a novel member of the IRAK family with the properties of an IRAK-kinase. Proc Natl Acad Sci U S A 99, 5567-5572.

Li, S., Wang, L., Berman, M., Kong, Y.Y., and Dorf, M.E. (2011). Mapping a dynamic innate immunity protein interaction network regulating type I interferon production. Immunity 35, 426-440.

Li, Y., Dai, J., Song, M., Fitzgerald-Bocarsly, P., and Kiledjian, M.
(2012). Dcp2 decapping protein modulates mRNA stability of the critical interferon regulatory factor (IRF) IRF-7. Mol Cell Biol 32, 1164-1172.

Liang, Q., Deng, H., Li, X., Wu, X., Tang, Q., Chang, T.H., Peng, H., Rauscher, F.J., 3rd, Ozato, K., and Zhu, F. (2011). Tripartite motif-containing protein 28 is a small ubiquitin-related modifier E3 ligase and negative regulator of IFN regulatory factor $7 . \mathrm{J}$ Immunol 187, 4754-4763.

Lin, S.C., Lo, Y.C., and Wu, H. (2010). Helical assembly in the MyD88-IRAK4-IRAK2 complex in TLR/IL-1R signalling. Nature 465, 885-890.

Litvak, V., Ratushny, A.V., Lampano, A.E., Schmitz, F., Huang, A.C., Raman, A., Rust, A.G., Bergthaler, A., Aitchison, J.D., and Aderem, A. (2012). A FOXO3-IRF7 gene regulatory circuit limits inflammatory sequelae of antiviral responses. Nature 490, 421-425.

Lo, C.C., Schwartz, J.A., Johnson, D.J., Yu, M., Aidarus, N., Mujib, S., Benko, E., Hyrcza, M., Kovacs, C., and Ostrowski, M.A. (2012). HIV Delays IFN-alpha Production from Human Plasmacytoid Dendritic Cells and Is Associated with SYK Phosphorylation. PLoS One 7, e37052.

Martinelli, E., Cicala, C., Van Ryk, D., Goode, D.J., Macleod, K., Arthos, J., and Fauci, A.S. (2007). HIV-1 gp120 inhibits TLR9-mediated activation and IFN-\{alpha\} secretion in plasmacytoid dendritic cells. Proc Natl Acad Sci U S A 104, 3396-3401.

Matsushita, K., Takeuchi, O., Standley, D.M., Kumagai, Y., Kawagoe, T., Miyake, T., Satoh, T., Kato, H., Tsujimura, T., Nakamura, H., et al. (2009). Zc3h12a is an RNase essential for controlling immune responses by regulating mRNA decay. Nature 458, 1185-1190.

Mitchell, A., Rentero, C., Endoh, Y., Hsu, K., Gaus, K., Geczy, C., McNeil, H.P., Borges, L., and Tedla, N. (2008). LILRA5 is expressed by synovial tissue macrophages in rheumatoid arthritis, selectively induces pro-inflammatory cytokines and IL-10 and is regulated by TNF-alpha, IL-10 and IFN-gamma. Eur J Immunol 38, 3459-3473.

Moynagh, P.N. (2009). The Pellino family: IRAK E3 ligases with emerging roles in innate immune signalling. Trends Immunol 30 , 33-42.

Nagasawa, M., Schmidlin, H., Hazekamp, M.G., Schotte, R., and Blom, B. (2008). Development of human plasmacytoid dendritic cells depends on the combined action of the basic helix-loop-helix factor E2-2 and the Ets factor Spi-B. Eur J Immunol 38, 2389-2400.

Nakahashi-Oda, C., Tahara-Hanaoka, S., Shoji, M., Okoshi, Y., Nakano-Yokomizo, T., Ohkohchi, N., Yasui, T., Kikutani, H., Honda, S.I., Shibuya, K., et al. (2012). Apoptotic cells suppress mast cell inflammatory responses via the CD300a immunoreceptor. J Exp Med. (In Press).

Nakajima, H., Samaridis, J., Angman, L., and Colonna, M. (1999). Human myeloid cells express an activating ILT receptor (ILT1) that associates with Fc receptor gamma-chain. J Immunol 162, 5-8.

Nakhaei, P., Mesplede, T., Solis, M., Sun, Q., Zhao, T., Yang, L., Chuang, T.H., Ware, C.F., Lin, R., and Hiscott, J. (2009). The E3 ubiquitin ligase Triad3A negatively regulates the RIG-I/MAVS signaling pathway by targeting TRAF3 for degradation. PLoS 
Pathog 5, e1000650.

Negishi, H., Ohba, Y., Yanai, H., Takaoka, A., Honma, K., Yui, K., Matsuyama, T., Taniguchi, T., and Honda, K. (2005). Negative regulation of Toll-like-receptor signaling by IRF-4. Proc Natl Acad Sci U S A 102, 15989-15994.

Ning, S., Campos, A.D., Darnay, B.G., Bentz, G.L., and Pagano, J.S. (2008). TRAF6 and the three C-terminal lysine sites on IRF7 are required for its ubiquitination-mediated activation by the tumor necrosis factor receptor family member latent membrane protein 1. Mol Cell Biol 28, 6536-6546.

Ninomiya-Tsuji, J., Kishimoto, K., Hiyama, A., Inoue, J., Cao, Z., and Matsumoto, K. (1999). The kinase TAK1 can activate the NIK-I kappaB as well as the MAP kinase cascade in the IL-1 signalling pathway. Nature 398, 252-256.

Oganesyan, G., Saha, S.K., Guo, B., He, J.Q., Shahangian, A., Zarnegar, B., Perry, A., and Cheng, G. (2006). Critical role of TRAF3 in the Toll-like receptor-dependent and -independent antiviral response. Nature 439, 208-211.

Osawa, Y., Iho, S., Takauji, R., Takatsuka, H., Yamamoto, S., Takahashi, T., Horiguchi, S., Urasaki, Y., Matsuki, T., and Fujieda, S. (2006). Collaborative action of NF-kappaB and p38 MAPK is involved in CpG DNA-induced IFN-alpha and chemokine production in human plasmacytoid dendritic cells. J Immunol 177, 4841-4852.

Pasquier, B., Launay, P., Kanamaru, Y., Moura, I.C., Pfirsch, S., Ruffie, C., Henin, D., Benhamou, M., Pretolani, M., Blank, U., et al. (2005). Identification of FcalphaRI as an inhibitory receptor that controls inflammation: dual role of FcRgamma ITAM. Immunity 22, $31-42$.

Pauls, E., Shpiro, N., Peggie, M., Young, E.R., Sorcek, R.J., Tan, L., Choi, H.G., and Cohen, P. (2012). Essential Role for IKKbeta in Production of Type 1 Interferons by Plasmacytoid Dendritic Cells. J Biol Chem 287, 19216-19228.

Pfirsch-Maisonnas, S., Aloulou, M., Xu, T., Claver, J., Kanamaru, Y., Tiwari, M., Launay, P., Monteiro, R.C., and Blank, U. (2011). Inhibitory ITAM signaling traps activating receptors with the phosphatase SHP-1 to form polarized "inhibisome" clusters. Sci Signal 4, ra24.

Pillai, S., Netravali, I.A., Cariappa, A., and Mattoo, H. (2012). Siglecs and immune regulation. Annu Rev Immunol 30, 357-392.

Rock, J., Schneider, E., Grun, J.R., Grutzkau, A., Kuppers, R., Schmitz, J., and Winkels, G. (2007). CD303 (BDCA-2) signals in plasmacytoid dendritic cells via a BCR-like signalosome involving Syk, SIp65 and PLCgamma2. Eur J Immunol 37, 3564-3575.

Rosental, B., Brusilovsky, M., Hadad, U., Oz, D., Appel, M.Y., Afergan, F., Yossef, R., Rosenberg, L.A., Aharoni, A., Cerwenka, A., et al. (2011). Proliferating cell nuclear antigen is a novel inhibitory ligand for the natural cytotoxicity receptor NKp44. J Immunol 187, 5693-5702.

Saitoh, T., and Akira, S. (2010). Regulation of innate immune responses by autophagy-related proteins. J Cell Biol 189, 925-935.

Saitoh, T., Satoh, T., Yamamoto, N., Uematsu, S., Takeuchi, O., Kawai, T., and Akira, S. (2011). Antiviral protein Viperin promotes Toll-like receptor 7- and Toll-like receptor 9-mediated type I interferon production in plasmacytoid dendritic cells. Immunity 34 , 352-363.
Sasai, M., Linehan, M.M., and Iwasaki, A. (2010). Bifurcation of Toll-like receptor 9 signaling by adaptor protein 3 . Science 329 , 1530-1534.

Sato, M., Hata, N., Asagiri, M., Nakaya, T., Taniguchi, T., and Tanaka, N. (1998). Positive feedback regulation of type I IFN genes by the IFN-inducible transcription factor IRF-7. FEBS Lett 441, 106-110.

Schnare, M., Holt, A.C., Takeda, K., Akira, S., and Medzhitov, R. (2000). Recognition of CpG DNA is mediated by signaling pathways dependent on the adaptor protein MyD88. Curr Biol 10, 1139-1142.

Schroeder, J.T., Bieneman, A.P., Xiao, H., Chichester, K.L., Vasagar, K., Saini, S., and Liu, M.C. (2005). TLR9- and FcepsilonRI-mediated responses oppose one another in plasmacytoid dendritic cells by down-regulating receptor expression. J Immunol 175, 5724-5731.

Shah, K.M., Stewart, S.E., Wei, W., Woodman, C.B., O'Neil, J.D., Dawson, C.W., and Young, L.S. (2009). The EBV-encoded latent membrane proteins, LMP2A and LMP2B, limit the actions of interferon by targeting interferon receptors for degradation. Oncogene 28, 3903-3914.

Shinohara, M.L., Lu, L., Bu, J., Werneck, M.B., Kobayashi, K.S., Glimcher, L.H., and Cantor, H. (2006). Osteopontin expression is essential for interferon-alpha production by plasmacytoid dendritic cells. Nat Immunol 7, 498-506.

Siednienko, J., Jackson, R., Mellett, M., Delagic, N., Yang, S., Wang, B., Tang, L.S., Callanan, J.J., Mahon, B.P., and Moynagh, P.N. (2012). Pellino3 targets the IRF7 pathway and facilitates autoregulation of TLR3- and viral-induced expression of type I interferons. Nat Immunol. (In Press).

Simhadri, V.R., Andersen, J.F., Calvo, E., Choi, S.C., Coligan, J.E., and Borrego, F. (2012). Human CD300a binds to phosphatidylethanolamine and phosphatidylserine, and modulates the phagocytosis of dead cells. Blood 119, 2799-2809.

Su, X., Li, S., Meng, M., Qian, W., Xie, W., Chen, D., Zhai, Z., and Shu, H.B. (2006). TNF receptor-associated factor-1 (TRAF1) negatively regulates Toll/L-1 receptor domain-containing adaptor inducing IFN-beta (TRIF)-mediated signaling. Eur J Immunol 36, 199-206.

Suzuki, N., Suzuki, S., Duncan, G.S., Millar, D.G., Wada, T., Mirtsos, C., Takada, H., Wakeham, A., Itie, A., Li, S., et al. (2002). Severe impairment of interleukin-1 and Toll-like receptor signalling in mice lacking IRAK-4. Nature 416, 750-756.

Tai, L.H., Goulet, M.L., Belanger, S., Toyama-Sorimachi, N., Fodil-Cornu, N., Vidal, S.M., Troke, A.D., McVicar, D.W., and Makrigiannis, A.P. (2008). Positive regulation of plasmacytoid dendritic cell function via Ly49Q recognition of class I MHC. J Exp Med 205, 3187-3199.

Tailor, P., Tamura, T., Kong, H.J., Kubota, T., Kubota, M., Borghi, P., Gabriele, L., and Ozato, K. (2007). The feedback phase of type I interferon induction in dendritic cells requires interferon regulatory factor 8. Immunity 27, 228-239.

Takaoka, A., Yanai, H., Kondo, S., Duncan, G., Negishi, H., Mizutani, T., Kano, S., Honda, K., Ohba, Y., Mak, T.W., et al. (2005). Integral role of IRF-5 in the gene induction programme activated by Toll-like receptors. Nature 434, 243-249.

Takeshita, F., Ishii, K.J., Kobiyama, K., Kojima, Y., Coban, C., Sasaki, S., Ishii, N., Klinman, D.M., Okuda, K., Akira, S., et al. (2005). 
TRAF4 acts as a silencer in TLR-mediated signaling through the association with TRAF6 and TRIF. Eur J Immunol 35, 2477-2485.

Takeuchi, O., and Akira, S. (2010). Pattern recognition receptors and inflammation. Cell 140, 805-820.

Tal, M.C., Sasai, M., Lee, H.K., Yordy, B., Shadel, G.S., and Iwasaki, A. (2009). Absence of autophagy results in reactive oxygen species-dependent amplification of RLR signaling. Proc Natl Acad Sci U S A 106, 2770-2775.

Talukder, A.H., Bao, M., Kim, T.W., Facchinetti, V., Hanabuchi, S., Bover, L., Zal, T., and Liu, Y.J. (2012). Phospholipid Scramblase 1 regulates Toll-like receptor 9-mediated type I interferon production in plasmacytoid dendritic cells. Cell Res 22, 1129-1139.

Tamura, T., Tailor, P., Yamaoka, K., Kong, H.J., Tsujimura, H., O'Shea, J.J., Singh, H., and Ozato, K. (2005). IFN regulatory factor-4 and -8 govern dendritic cell subset development and their functional diversity. J Immunol 174, 2573-2581.

Taniguchi, T., Ogasawara, K., Takaoka, A., and Tanaka, N. (2001). IRF family of transcription factors as regulators of host defense. Annu Rev Immunol 19, 623-655.

Tsujimura, H., Tamura, T., and Ozato, K. (2003). Cutting edge: IFN consensus sequence binding protein/IFN regulatory factor 8 drives the development of type I IFN-producing plasmacytoid dendritic cells. J Immunol 170, 1131-1135.

Tun-Kyi, A., Finn, G., Greenwood, A., Nowak, M., Lee, T.H., Asara, J.M., Tsokos, G.C., Fitzgerald, K., Israel, E., Li, X., et al. (2011). Essential role for the prolyl isomerase Pin1 in Toll-like receptor signaling and type I interferon-mediated immunity. Nat Immunol 12, 733-741.

Uematsu, S., Sato, S., Yamamoto, M., Hirotani, T., Kato, H., Takeshita, F., Matsuda, M., Coban, C., Ishii, K.J., Kawai, T., et al. (2005). Interleukin-1 receptor-associated kinase-1 plays an essential role for Toll-like receptor (TLR)7- and TLR9-mediated interferon-\{alpha\} induction. J Exp Med 201, 915-923.
Wan, Y., Kim, T.W., Yu, M., Zhou, H., Yamashita, M., Kang, Z., Yin, W., Wang, J.A., Thomas, J., Sen, G.C., et al. (2011). The dual functions of IL-1 receptor-associated kinase 2 in TLR9-mediated IFN and proinflammatory cytokine production. J Immunol 186, 3006-3014.

Wang, C., Chen, T., Zhang, J., Yang, M., Li, N., Xu, X., and Cao, X. (2009). The E3 ubiquitin ligase Nrdp1 'preferentially' promotes TLR-mediated production of type I interferon. Nat Immunol 10, 744-752.

Wang, R.P., Zhang, M., Li, Y., Diao, F.C., Chen, D., Zhai, Z., and Shu, H.B. (2008). Differential regulation of IKK alpha-mediated activation of IRF3/7 by NIK. Mol Immunol 45, 1926-1934.

Watarai, H., Sekine, E., Inoue, S., Nakagawa, R., Kaisho, T., and Taniguchi, M. (2008). PDC-TREM, a plasmacytoid dendritic cell-specific receptor, is responsible for augmented production of type I interferon. Proc Natl Acad Sci U S A 105, 2993-2998.

Yan, D., Wang, X., Luo, L., Cao, X., and Ge, B. (2012). Inhibition of TLR signaling by a bacterial protein containing immunoreceptor tyrosine-based inhibitory motifs. Nat Immunol. (In Press).

Yang, Y., Liu, B., Dai, J., Srivastava, P.K., Zammit, D.J., Lefrancois, L., and Li, Z. (2007). Heat shock protein gp96 is a master chaperone for toll-like receptors and is important in the innate function of macrophages. Immunity 26, 215-226.

Yoshizaki, M., Tazawa, A., Kasumi, E., Sasawatari, S., Itoh, K., Dohi, T., Sasazuki, T., Inaba, K., Makrigiannis, A.P., and Toyama-Sorimachi, N. (2009). Spatiotemporal regulation of intracellular trafficking of Toll-like receptor 9 by an inhibitory receptor, Ly49Q. Blood 114, 1518-1527.

Yu, Y., and Hayward, G.S. (2010). The ubiquitin E3 ligase RAUL negatively regulates type $\mathrm{i}$ interferon through ubiquitination of the transcription factors IRF7 and IRF3. Immunity 33, 863-877.

Zhang, J., Xu, L.G., Han, K.J., Wei, X., and Shu, H.B. (2004). PIASy represses TRIF-induced ISRE and NF-kappaB activation but not apoptosis. FEBS Lett 570, 97-101. 